Çukurova Üniversitesi Mühendislik Mimarlık Fakültesi Dergisi, 32(4), ss. 99-106, Aralık 2017

Çukurova University Journal of the Faculty of Engineering and Architecture, 32(4), pp. 99-106, December 2017

\title{
İnce Cidarı Basınçlı Kapların Dış Yükler Altında Mekanik Davranışlarının Deneysel ve Sayısal Olarak İncelenmesi
}

\author{
İbrahim ÇAYIROĞLU ${ }^{* 1}$, Ferdi YILDIRIM ${ }^{2}$, Sadettin ŞAHİ ${ }^{3}$ \\ ${ }^{1}$ Karabük Üniversitesi, Mühendislik Fakültesi, Mekatronik Bölümü, Karabük \\ ${ }^{2}$ Aksaray Üniversitesi, Ortaköy M.Y.O., Makine Programı, Aksaray \\ ${ }^{3}$ Kırlkkale Üniversitesi, Mühendislik Fakültesi, Metalurji ve Malzeme Bölümü, Kırıkkale
}

$\ddot{\mathbf{O} z}$

Geliş tarihi: 04.04.2017_ Kabul tarihi: 19.12.2017

Bu çalışmada ince cidarlı basınçlı kapların dış yükler altındaki davranışları incelenip, yük taşıma, enerji absorbe etme gibi alanlarda kullanılıp kullanılmayacağına yönelik yeni bir bakış açısı ele alınmıştır. Bu durum tıpkı bir balonun boşken yük taşımaması fakat şişirildiğinde yük taşıması olayına benzemektedir. $\mathrm{Bu}$ amaçla laboratuarda yapılan deneylerde ince cidarlı alüminyum silindir tüplere, çeşitli basınçlarda hava basılıp üzerine eğme ve basma kuvvetleri uygulanarak konuma bağlı davranışları incelenmiştir. İç basınç artışının, dış yükleri taşımada ne kadar katkısının olduğu deneysel olarak gösterilmiştir. Ardından deneysel sonuçları nümerik hesaplarla karşılaştırmak için, sonlu elemanlar tekniği ile analizler yapılmış ve sonuçları karşılaştırılmıştır. Deneysel sonuçlar ile nümerik sonuçların benzerlik gösterdiği görülmüştür. Daha ileri çalışmalar için bu yöntemin nerelerde kullanılabileceği ele alınıp gerçek hayattaki pratik uygulamaları araştırılabilir.

Anahtar Kelimeler: Basınçlı kaplar, Malzeme mekaniği, Sonlu elemanlar analizi

\section{Experimental and Numerical Analysis of the Mechanical Behaviour of Thin Walled Pressure Vessels under External Loads}

\begin{abstract}
In this study, the behaviour of thin-walled pressure vessels under external loads have been analysed and a new perspective has been discussed to find out whether or not it could be used in areas such as carrying loads, energy absorption. This situation is similar to the fact that; a balloon can not carry weight when empty but it can when it's inflated. For this purpose, in the experiments conducted in the laboratory with the thin-walled aluminum cylinder tubes, air has been pumped in various pressures and positiondependent behavior has been analysed by applying bending and compressive forces. The contribution of an increase in the internal pressure to carry external loads has been shown experimentally. Following, in order to draw a comparison with numeric calculations, analysis have been made with finite elements method and the results have been compared. The experimental and numerical results have shown similarity. For further studies, the practical applications of real life can be searched for where this method can be used.
\end{abstract}

Keywords: Pressure vessels, Mechanics of material, Finite element analysis

\footnotetext{
*Corresponding author (Sorumlu yazar): İbrahim ÇAYIROĞLU, icayiroglu@karabuk.edu.tr
} 


\section{GíRiş}

Makina parçalarının optimal tasarımında ayn ağırlık için daha fazla yük taşınması önemli bir kriterdir. Kullanılan malzeme ve tasarım iyileştirmelerinin son sınırına gelindiği durumlarda, daha ileri gidebilmek için yeni yöntemlere ve farklı bakış açılarına ihtiyaç vardır.

Bu çalışmada, bu yönde katkı sağlamak için farklı bir tasarım anlayışı sunulmuştur. Bu amaçla ince cidarlı deney tüplerine farklı değerlerde hava basıncı uygulanarak, basma ve eğilme yükleri altında davranışları incelenmiştir. Deney sonuçları nümerik sonuçlarla karşılaştırılmış, basınç artışının mukavemet artışı üzerindeki etkisi gösterilmiştir. Yöntemin gerçek yapılar üzerinde nasıl kullanılabileceği bundan sonrası için bir araştırma konusu olabilecektir (Şekil 1).

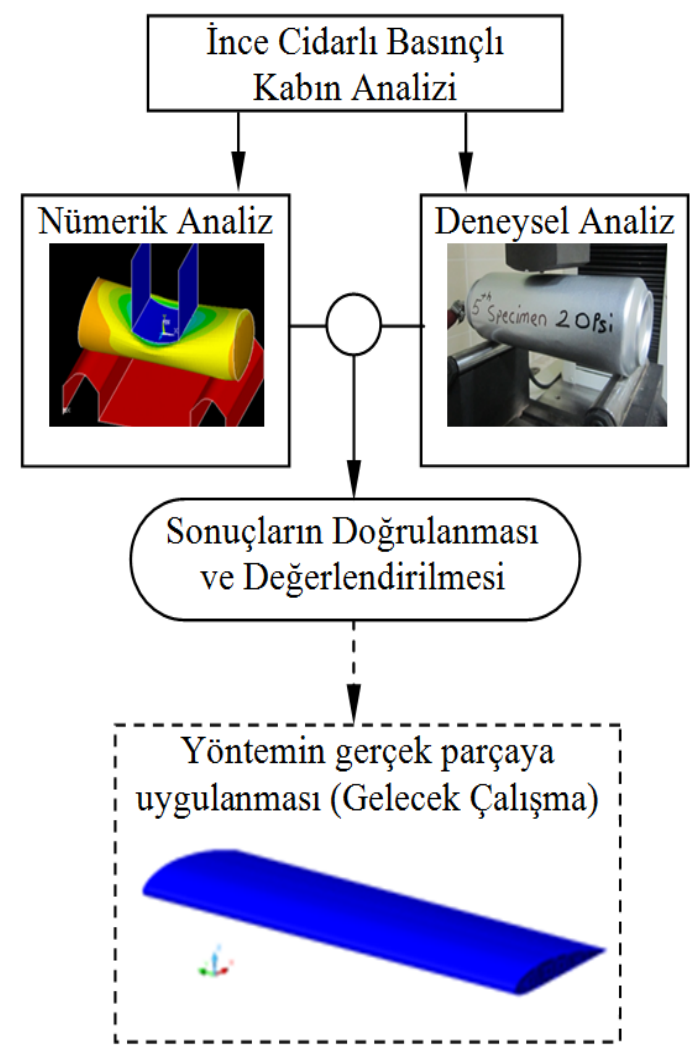

Şekil 1. Çalışmanın genel yapısı
Konunun literatür geçmişine bakıldığında, ince cidarlı basınçlı kapların mukavemet artışı amacıyla kullanılmasına yönelik direk bir çalışma bulunamamıştır. Metal yapıların mukavemetini artırmak için daha farklı yöntemler denenmektedir. Bunlar daha çok yapının içerisine çeşitli malzemeler doldurarak (Alüminyum köpük, PVC köpük, Fiber malzeme) mukavemet artış1 sağlanmaya yönelik çalışmalardır. Basınçlı kaplar ile ilgili olarak daha çok basınç artışının cidar üzerindeki etkileri, darbe emme ve patlatma testleri üzerine çalışmalar vardır. $\mathrm{Bu}$ konularda aşağıdaki çalışmalar dikkati çekmektedir. Basınç artışının dış yük artışı üzerinde bir çalışma yoktur.

Zhang ve Yu [1] yaptıkları çalışmada, ince cidarlı yapılarda iç basınç etkisinin enerji emilimine olan etkisini araştırmışlardır. Çalışmalarında kullanmış oldukları tüplere eksenel olarak bası kuvveti uygulamışlardır. Tüp içerisindeki iç basıncın artışına bağlı olarak ezilme sonucu oluşan şekil değişim modları, elmas şeklinde, keskin köşe şeklinde, yuvarlak köşe ve halka modları şeklinde olmuştur. Graczykowski ve arkadaşları [2] ince cidarlı yapıların içine hava doldurarak ve çarpışma esnasında havayı kontrollü olarak serbest bırakıp darbeyi sönümlemeye çalışmışlardır. Palanivelu ve arkadaşları [3] geri dönüştürülebilir boş metal içecek kutularının yakınından yakın mesafeli patlama testleri yaparak, kutuların enerji emilimini ve ezilme davranışlarını incelemişlerdir. Eruslu [4] yaptığı çalışmada ince cidarlı tüplerin iki boyutlu ve üç boyutlu sonlu elemanlar modellerini oluşturarak, tüplerin iç basınç etkisi altında hasar analizini yapmıştır. Tanboğa [5] yaptığı çalışmada, çok yüksek iç basınç altındaki kompozit tüpün üzerine, darbe tesirli bir parçacı̆̆ın etki etmesi esnasında, kompozit ve alüminyum katmanlar da oluşan gerilme ve şekil değiştirme davranışını simülasyon yoluyla araştırmıştır. Atlı [6] yaptığı çalışmada, iç ve dış basınç altındaki çok katmanlı kompozit tüplerin gerilme analizi için analitik bir yaklaşım sunmuştur. Çuhadar [7] yaptığı çalışmada, içten basınca maruz kapların, değişik malzemeler için yapılan analizler sonucu optimum cidar kalınlığını elde etmeye çalışmıştır.

$\mathrm{Bu}$ çalışmada basınçlı kabın eğilme ve basma yükleri altında, içerisindeki basınç artışının dış 
yükleri karşılamadaki etkisi hem deneysel olarak hem de nümerik olarak incelenmiştir. Numerik analizlerin yapılmasında Ansys/Ls-Dyna Explicit programı kullanılmıştır.

\section{MATERYAL VE METOD}

Üç nokta eğme deneylerinde ve basma deneylerinde, cidar kalınlığ $\mathrm{t}=0,15 \mathrm{~mm}$, uzunluğu $\mathrm{L}=167 \mathrm{~mm}$, çap $1 \mathrm{D}=65 \mathrm{~mm}$ olan alüminyum tüpler kullanılmıştır (Şekil 2). Tüplerin içerisine hava doldurmak için uç kısmına sibop monte edilmiştir. Yapılan deneylerde tüplere sirasıyla 0, 5, 10, 15, $20,25,30$ psi değerlerinde hava basılmış eğilme ve basma deneylerine tabi tutulmuştur.

\section{1. Üç Nokta Eğme Deneyi}

Üç nokta eğilme deneyinde üst basma çenesi $5 \mathrm{~mm} /$ dak hızla hareket ettirilmiş ve bu esnada tüpde oluşan tepki kuvveti ölçülmüştür (Şekil 3). Tüplerdeki iç basınç sıfırdan 30 psi değerine kadar 5 psi'lık adımlarla arttırılarak uygulanmıştır. Her basınç adımında 2 tane tüp denenmiş ve elde edilen verilerin ortalamaları alınmıştır. Tüpün içerisindeki basınç arttıkça uyguladığı tepki kuvveti de artmaktadır. Basınç artışının tüpde oluşturduğu direnç kuvvetinin değişimi Şekil 4'de grafik olarak verilmiştir. Tüpün içerisindeki basınç 0 psi'dan 30 psi çıktığında oluşan tepki kuvveti de 100 N'dan 900 N'a çıkmış, yani 9 kat artmıştır.

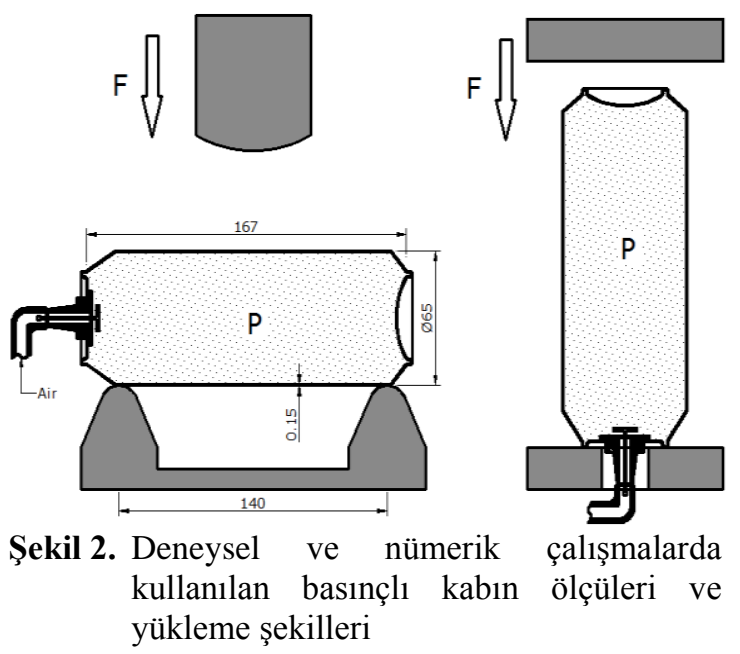

\subsection{Basma Deneyi}

Basma deneyinde de üst çene $5 \mathrm{~mm} /$ dak hızla hareket ettirilmiş, bu esnada tüpde oluşan tepki kuvveti grafiksel olarak elde edilmiştir. Tüp içerisine uygulanan basınç değerleri yine $(0,5,10$, $15,20,25,30$ psi) olarak alınmış ve her deneme iki kez tekrar edilmiştir (Şekil 5).

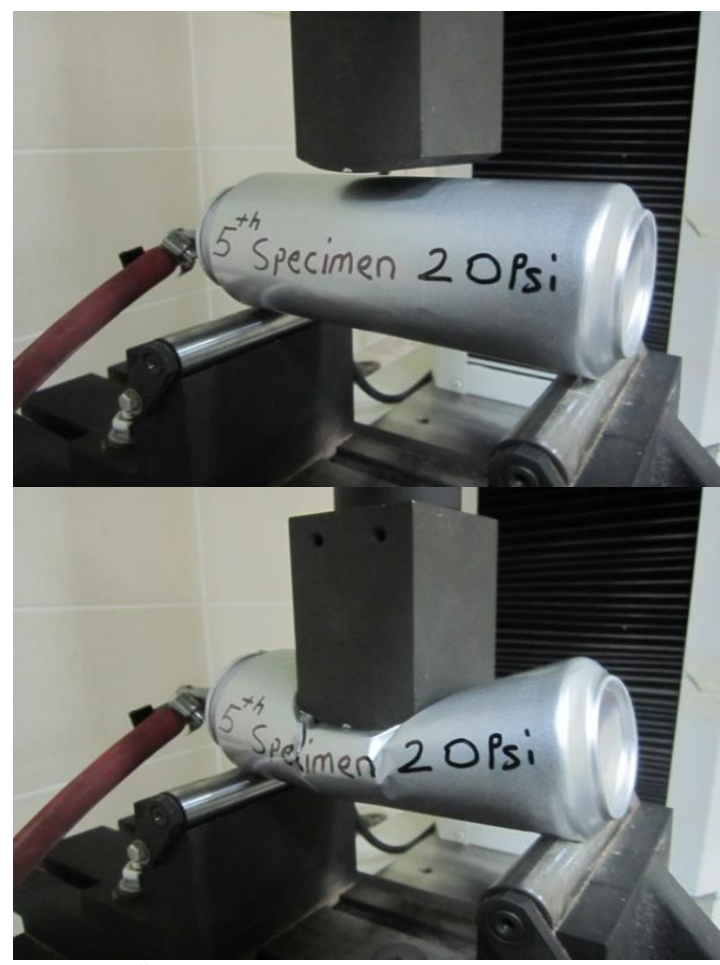

Şekil 3. Üç noktadan uygulanan eğme deneyi

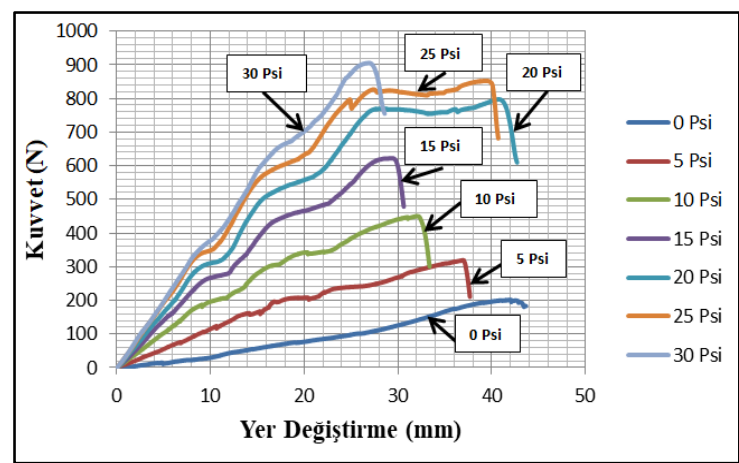

Şekil 4. Farklı basınçlar için üç nokta eğme deneyinden elde edilen yer değişimkuvvet grafikleri 
Tüm basınç değerlerindeki yer değiştirme ve kuvvet grafikleri incelendiğinde (Şekil 6), tüp 2-3 mm ezildiğinde 0 ve 5 psi basınçlarda delinme, daha üst basınçlarda ise patlama gerçekleşmektedir. 0 ve 5 psi da sadece delinme olayı olduğu için tüpün cidarları içinde basınç olmasa bile yük taşımaya devam etmektedir. Daha yüksek basınçlarda tüp tamamen yarıldığı için cidar direnci oluşmamaktadır. Grafiğin tepe noktaları incelendiğinde 0 psi dan 5 psi geçildiğinde direnç kuvveti 3 kat artmaktadır. Benzer şekilde 5 psi dan 30 psi çıkıldığında ise 1,33 kat artmaktadır. Buradan çıkarılan sonuç ince cidarlı bir tüp, basınç altında yük taşımada kullanılacaksa içerisine çok fazla basınç koymaya gerek yoktur. Çok az düzeyde bir basınç ezilme direncini yeterince artırmaktadır. Düşük basınçlarda metal tüpte oluşan delinmelere karşı iç kısmında elastik bir sızdırmazlık elemanı kullanmak faydalı olacaktır.

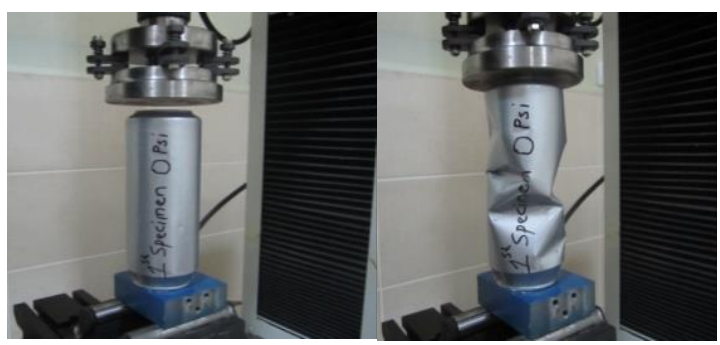

Şekil 5. Basma deneyi

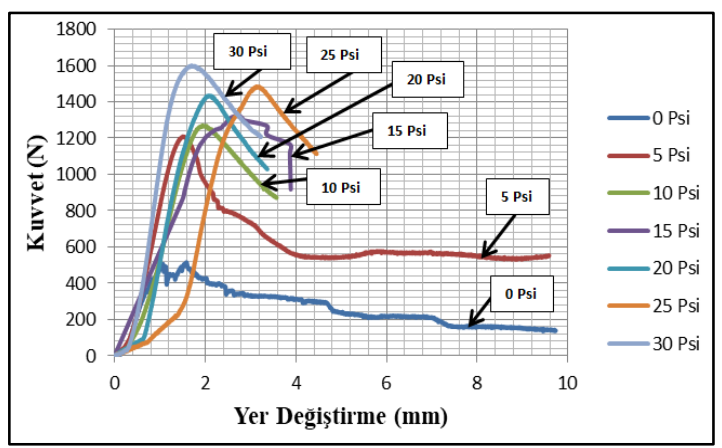

Şekil 6. Basma deneyinde farklı basınçlarda elde edilen kuvvet-yerdeğişim grafikleri

\subsection{Sonlu Elemanlar Analizi}

Parça iç basınca sahip iken, dış yüklere maruz kalması, üzerinde çok farklı gerilmelerin oluşmasına yol açmaktadır. Bu durumu analitik olarak çözmek non-lineer davranışlar nedeniyle neredeyse imkânsızdır. Bu hesaplamaları sonlu elemanlar ile sayısal olarak yapmak mümkündür. Sonlu elemanlar metodu karmaşık yapılarda ve kompleks yüklemelerde etkin bir şekilde kullanılabilir. İyi bir modelleme yapıldığında analitik ve deneysel metotlardan çok daha hassas sonuçlar vermektedir.
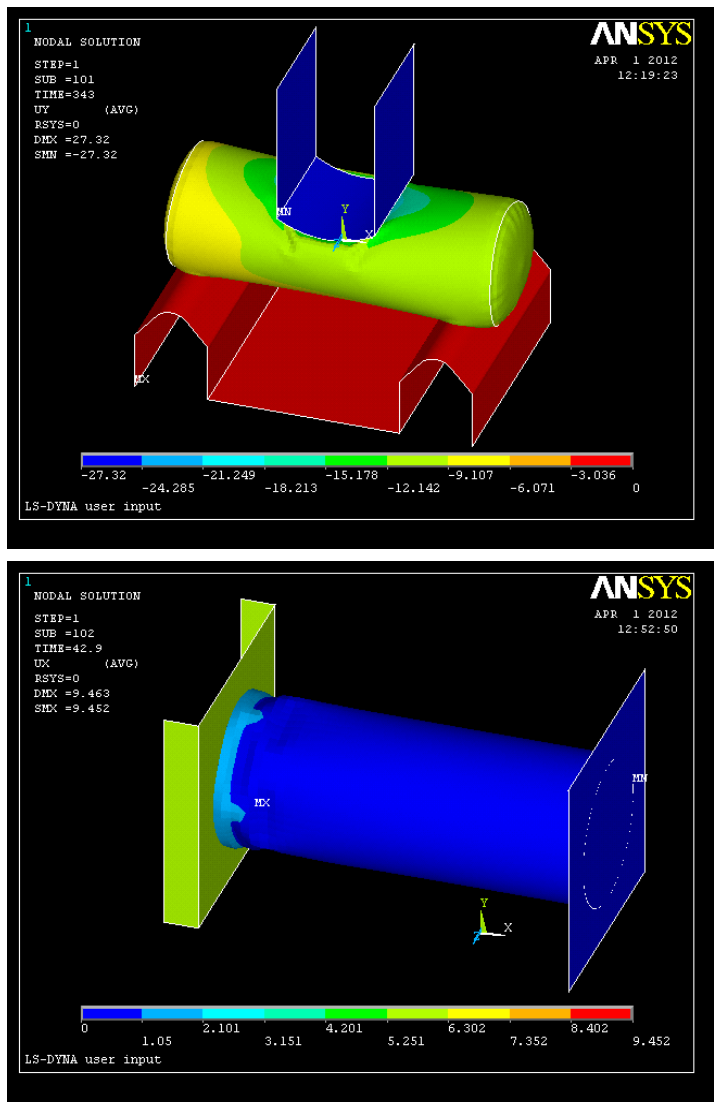

Şekil 7. Eğilme ve basma yükleri için sonlu elemanlar analizleri

Sonlu elemanlar analizi için ASYS/Ls-Dyna APDL programı Shell elementler kullanılarak yapılmıştır (Şekil 7). Hareketli üst basma çenesi ile sabit alt çeneler rijit özelliğe ayarlanmıştır. Alüminyum tüpün elastisite modülü $69 \mathrm{GPa}$, yoğunluğu $2720 \mathrm{~kg} / \mathrm{m}^{3}$, kayma modülü 0,833 , poisson oran 10,34 ve akma mukavemeti $285 \mathrm{MPa}$ olarak ayarlanmıştır. 
Sayısal analizde tüp model içerisine deneysel çalışmada olduğu gibi 0-30 Psi değerlerinde basınçlar uygulanmıştır. Analizde tüpün patlaması gibi ani bir basınç düşmesi olayı görülmediği için, sayısal analizle deneysel sonuçların her yönüyle karşılaştırılması mümkün olmamıştır. Karşılaştırmanın yapılabilmesi için deneysel sonuçlardan elde edilen zamana bağlı kuvvet yer değişim grafiği, analizi yapılan tüpün üzerine uygulanmış ve elde edilen yerdeğişim (deplasmanlar) grafikleri kullanılmıştır. Sayısal analizdeki yerdeğişim grafiklerinin deneysel sonuçlarda elde edilen grafikler ile benzer olduğu görülmüştür. Sonraki bölümde deneysel grafikler ile sayısal analiz grafikleri karşılaştırmalı olarak verilmişstir.

\section{BULGULAR VE TARTIŞMA}

Deneysel ve sayısal sonuçlardan eğilme durumu için elde edilen grafikler karşılaştırıldığında birbirine yakın çıktığı gözükmektedir (Şekil 8). Her iki analizde de kuvvet değerleri aynı alınmıştır. Yani deneysel sonuçta hareketli çene $5 \mathrm{~mm} / \mathrm{s}$ hızla ilerlerken oluşan kuvvet ve yerdeğişim grafiği çizilmiştir. Aynı kuvvetin zamana göre değişimi nümerik analizde de uygulanarak yer değişim sonuçları elde edilmiştir. $\mathrm{Bu}$ nedenle grafiklerin kuvvet ekseni aynı değerlere sahip iken (tepe noktaları aynı olmak zorundadır) yerdeğişimin ne kadar benzer olduğu ortaya konulmuştur. 0 Psi basınç grafiği hariç diğer grafiklerin hemen hemen yakın çıktığ1 gözükmektedir. 0 Psi'da kabın içerisinde hiç basınç olmadığı için kabın cidarlarında oluşan ezilmeler öngörülemez olarak ezilmektedir. Yani ezilme esnasında yüzeyler içeri ya da dışarı rastgele yönelir. Basınçlı bir kapta yüzeyler direk dışarı zorlanır. Yine de $150 \mathrm{~N}$ kadar olan kısımda bir benzerlik mevcuttur.
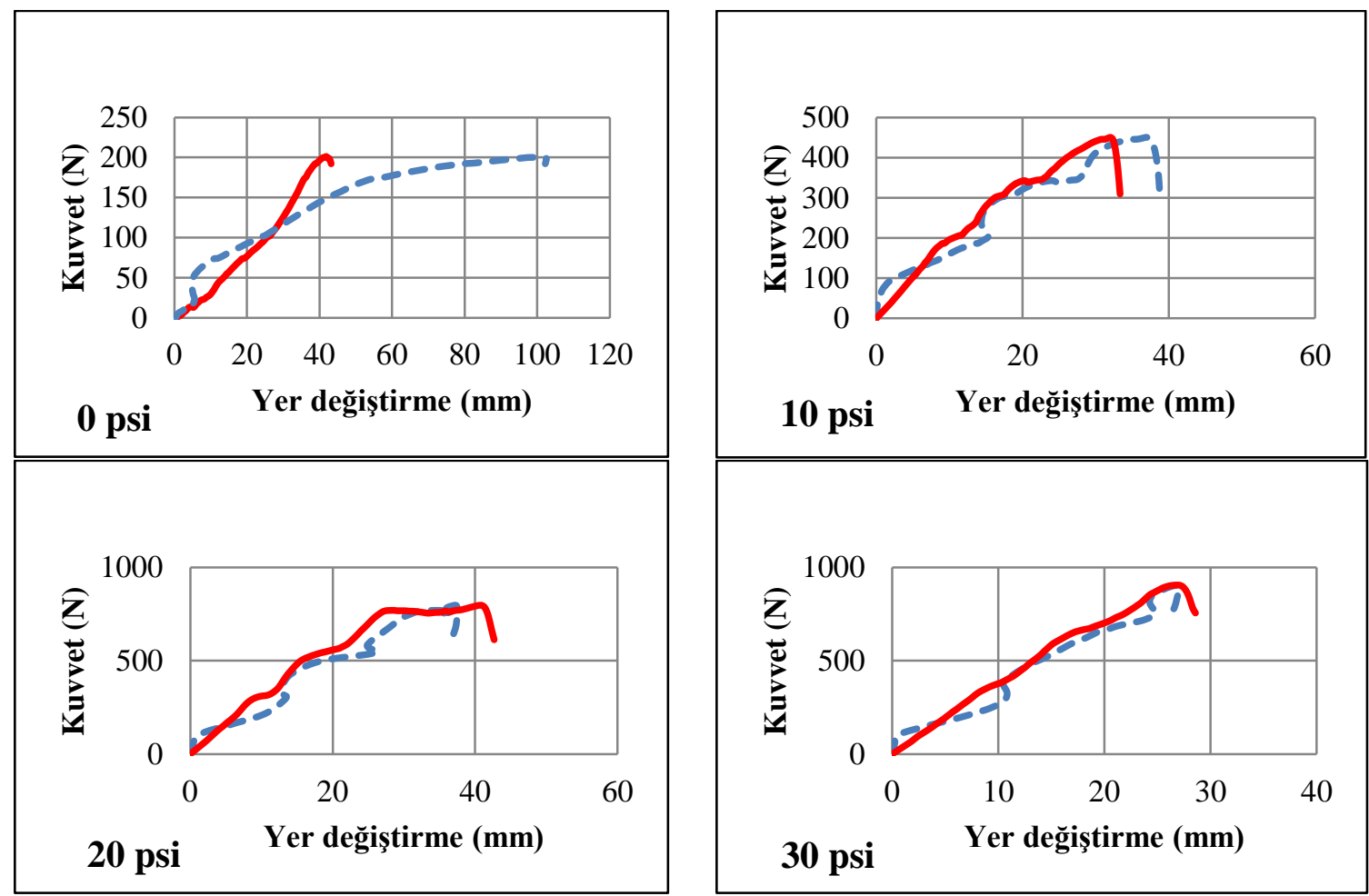

Şekil 8. Üç nokta eğme deneyi ve sayısal analizden elde edilen kuvvet-yerdeğişim grafiklerinin karşılaştırılması. Deneysel sonuçlar (L), sayısal sonuçlar (.......) şeklinde gösterilmiştir 
Deneysel ve sayısal sonuçlar eksenel basma yükü için karşılaştırılırsa grafiklerin yine bezer çıktığı söylenebilir. Daha çok teorik bir sonucu gösteren sayısal analizlerde grafiğin eğimi yüksek çıkmışıtr. Bunun sebebi kabın cidarlarına kuvvet dik olarak

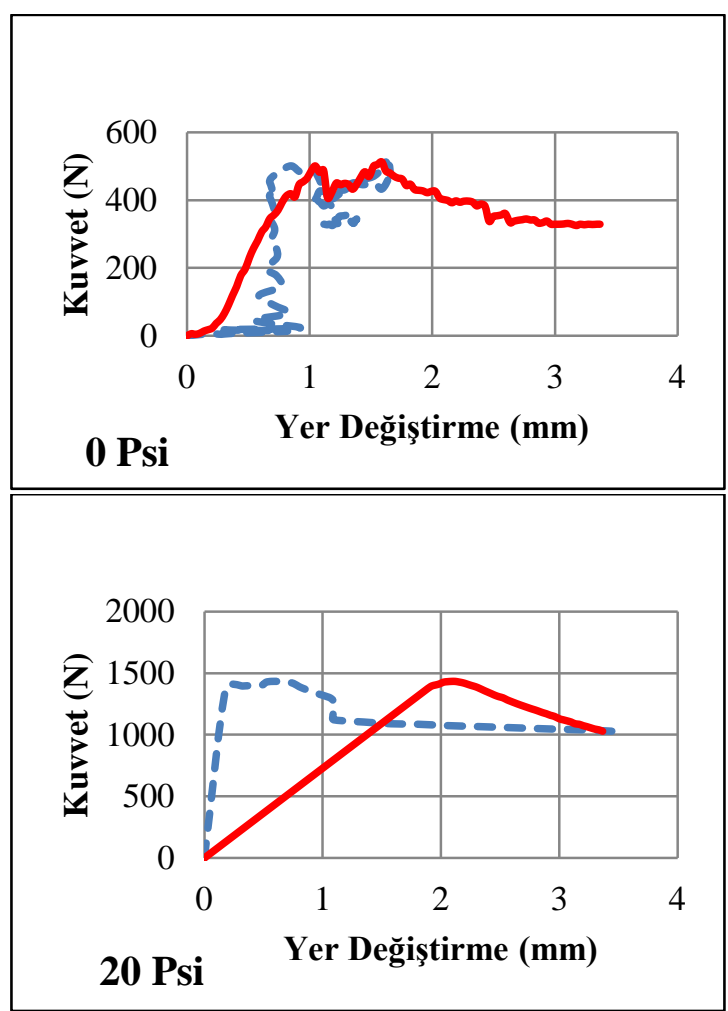

uygulandığından malzeme teorik olarak ezilmeye direk bir direnç göstermektedir. Oysa gerçekte yüzeylerdeki en ufak bir sapma cidardaki eğilmeyi kolaylaştırır ve bunun sonucu basmaya karşı direnç azalır (Şekil 9).

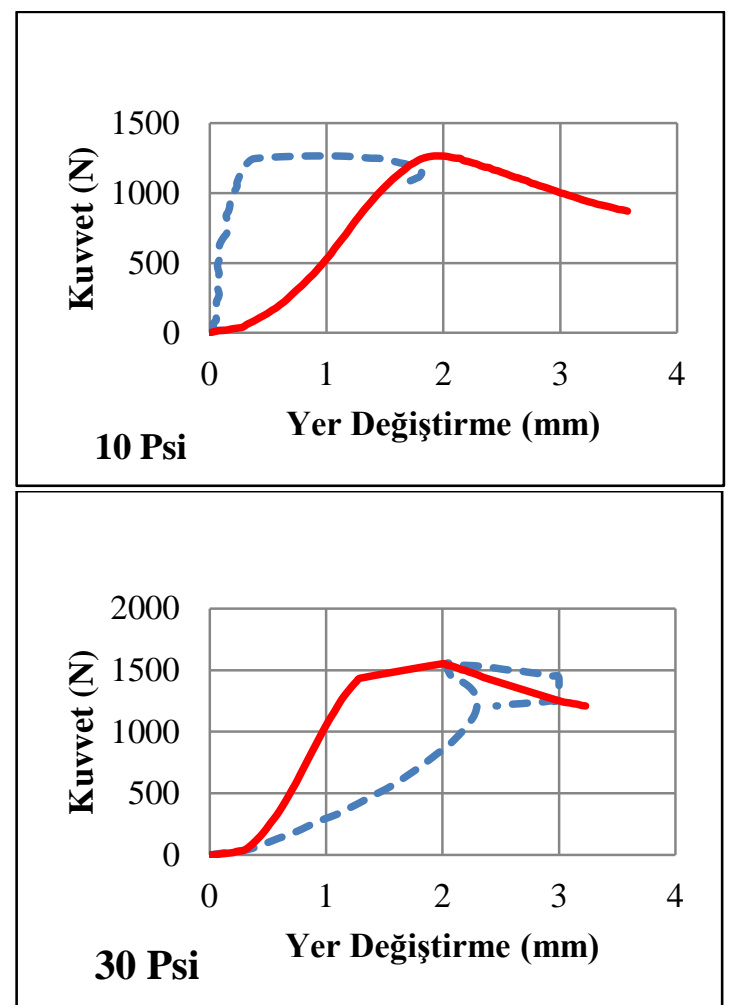

Şekil 9. Basma deneyi analiz ve test sonuçlarının grafiksel olarak karşılaştırılması. Deneysel sonuçlar ( _ ), sayısal sonuçlar ( . . . . . . . . ) şeklinde gösterilmiştir

\section{SONUÇLAR}

Bu çalışmada ince cidarlı basınçlı tüplerin üzerine uygulanan yüklere karşı göstermiş olduğu direnç ve tüpün mukavemet artışı incelenmiştir. İncelemede hem deneysel hemde sayisal metodlar kullanılmıştır. Sayısal hesaplamalarda sonlu elemanlar tekniğgi kullanılmıştır. $\mathrm{Bu}$ tekniğin vermiş olduğu sonuçlar deneysel sonuçları doğrulamıștır. Bu çalışmanın devamı olarak ileride yapılacak olan basınç hücreli tasarım çalışmalarında, sonlu elemanlar tekniği buradaki yöntemlere bağlı kalarak güvenle kullanılabileceği gösterilmiştir.
Deneylerde üç nokta eğme testlerinden elde edilen grafiksel sonuçlarda içi boş yani basınç uygulanmamış bir tüpün taşıyabileceği maksimum yük $201 \mathrm{~N}$ iken, 30 Psi ile basınçlandırılmış tüpün taşıyabileceği maksimum yük ise $905 \mathrm{~N}$ olarak elde edilmiştir.

Basma testlerinde elde edilen grafiksel sonuçlarda ise basınç uygulanmamış tüpün taşıyabileceği maksimum yük $516 \mathrm{~N}$ iken, 30 Psi ile basınçlandırılmış tüpün taşıyabileceği maksimum yükün $1595 \mathrm{~N}$ seviyesine çıktığı gözlemlenmiştir.

Elde edilen sonuçlara göre içinde basınç olan tüpler bir parçayı ya da yapıda dış yüklere karşı 
daha mukavemetli olması için kullanılabilecektir. Bundan sonrası için yapılacak çalışmalar sonlu elemanlar tekniği ile içinde basınç hücresi bulunan parça ya da sistemleri tasarlamaktır.

\section{KAYNAKLAR}

1. Zhang, X.W., Yu, T.X., 2009. Energy Absorption of Pressurized Thin-walled Circular Tubes under Axial Crushing, International Journal of Mechanical Sciences, 51, 335-349.

2. Graczykowski, C., Chmielewski, R., Holnicki, J., 2004. Controlled Impact Absorption in Adaptive Pressurized Structures, European Congress on Computational Methods in Applied Sciences and Engineering ECCOMAS, 1-10.

3. Palanivelu, S., Paepegem, W.V., Degrieck, J., Reymen, B., Ndambi, J.M., Vantomme, J., Kakogiannis, D., Wastiels, J., Hemelrijck, D.V., 2011. Close-range Blast Loading on Empty Recyclable Metal Beverage Cans for use in Sacrificial Cladding Structure, Engineering Structures, 33, 1966-1987.

4. Eruslu, S., 2008. İnce Cidarlı Basınçlı Tüplerin Sonlu Elemanlar Yöntemiyle Analizi, Pamukkale Üniversitesi, Mühendislik Fakültesi, Mühendislik Bilimleri Dergisi, 14 (2), 162-174.

5. Tanboğa, B., 2007. Darbe Altındaki Elyaf Takviyeli Kompozit Tüpün Sonlu Elemanlar Modellemesi ile İncelenmesi, Yüksek Lisans Tezi, Marmara Üniversitesi, Fen Bilimleri Enstitüsü.

6. Atl1, A., 2010. Analytical Investigaton of Multi-layer Composite Tubes Subject to Pressure, Ms. Thesis Submitted to the Graduate School of Natural and Applied Sciences of Atilim University.

7. Çuhadar, B., Akkuş, N., 2005. İçten Basınca Maruz Kapların Dizaynı, Bitirme Tezi, Dokuz Eylül Üniversitesi, Mühendislik Fakültesi. 
